\title{
Combustion Derived SrTiO3: Synthesis, Characterization and Evaluation of Electrochemical Behavior Towards Quantification of $\mathrm{Hg}$ (II) Ions
}

\section{Kusuma Manjunath ${ }^{1 *}$, Prashanth Shivappa Adarakatti ${ }^{1,2}$, Pandurangappa Malingappa ${ }^{1}$, Gujjarahalli Thimmanna Chandrappa ${ }^{1}$}

${ }^{1}$ Department of Chemistry, Central College Campus, Bangalore University, Bengaluru, India

${ }^{2}$ Solid State and Structural Chemistry Unit, Indian Institute of Science (IISc), Bengaluru, India

*Correspondence: kusm.mn@gmail.com

\begin{abstract}
In this work, we are reporting the synthesis of porous $\mathrm{SrTiO}_{3}$ nanoparticles by using solution combustion route employing strontium nitrate and titanium-peroxo complex as oxidizer. The results of physico-analytical techniques revealed that $\mathrm{SrTiO}_{3}$ have a relatively small particle size, good dispersibility and diminished agglomeration. Powder Xray diffraction pattern shows cubic perovskite structure (space group Pm3m) and the morphology was observed using a scanning electron microscope. The band gap of $3.24 \mathrm{eV}$ was calculated using the diffuse reflectance spectrum. The surface area $\left(\sim 26.51 \mathrm{~m}^{2} / \mathrm{g}\right)$ of $\mathrm{SrTiO}_{3}$ was measured by BET method. $\mathrm{SrTiO}_{3}$ nanoparticles show violet-blue-green photoluminescence emission spectrum at room temperature. The photocatalytic degradation was carried out to investigate the photocatalytic activity of $\mathrm{SrTiO}_{3}$ under UV-light and evaluated for the electrochemical quantification of $\mathrm{Hg}$ (II) ions in aqueous solution using differential pulse anodic stripping voltammetry. The results reveal that $\mathrm{SrTiO}_{3}$ nanoparticles show better quantification result for $\mathrm{Hg}($ II) ions.
\end{abstract}

\section{Graphical Abstract}

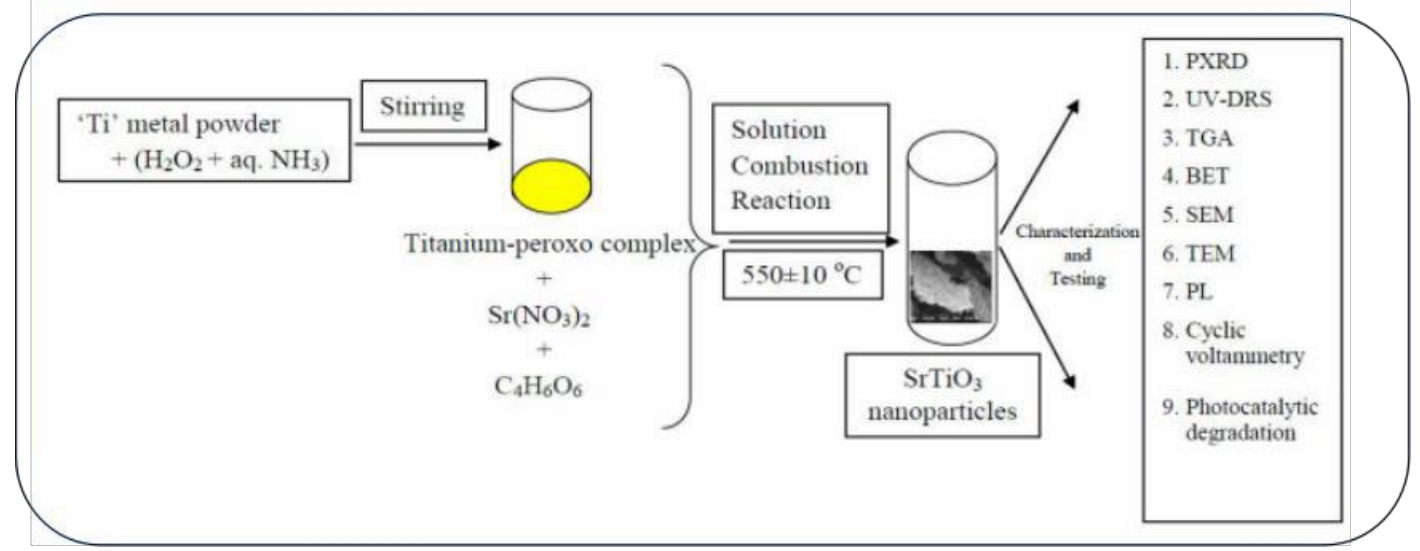

Keywords: Solution combustion; strontium titanate; photoluminescence; photocatalysis; electrochemical behavior

Received: Mar 8, 2019 Accepted: May 13, 2019 Online: May 27, 2019

\section{Introduction}

In recent years, higher consideration has been paid for the synthesis and characterization of materials with a perovskite structure, which is the exciting group of oxides ${ }^{[1]}$. Oxides of a transition metals having perovskite cubic system show a significant class of materials with distinctive properties ${ }^{[2]}$. Strontium titanate $\left(\mathrm{SrTiO}_{3}\right)$ is a simple cubic perovskite structured material and as a semiconductor, it represents indirect band gap that normally measures from 3.2 to $3.4 \mathrm{eV}$ [3]. The structure of $\mathrm{SrTiO}_{3}$ is literally cubic perovskite at high temperatures and at a critical temperature a secondorder phase transition takes place which differs between the compounds. The $\mathrm{SrTiO}_{3}$ material presents one of the finest and completely examined phase transitions in the crystal and is a part of developing crystals along with $\mathrm{KMnF}_{3}$,

Copyright (C) 2019 Kusuma Manjunath et al. This is an Open Access article distributed under the terms of the Creative Commons AttributionNonCommercial 4.0 International License (http://creativecommons.org/licenses/by-nc/4.0/), permitting all non-commercial use, distribution, and reproduction in any medium, provided the original work is properly cited. 
$\mathrm{LaAlO}_{3}$ and $\mathrm{NdAlO}_{3}$ which all possess the general aspects ${ }^{[4]}$. Thus, $\mathrm{SrTiO}_{3}$ has gained much consideration due to its feasible applications in diversified microelectronic heterostructure devices, with low leakage current and high dielectric constant. It is also used as solar cells ${ }^{[5]}$, oxygen sensors ${ }^{[6]}$, thermoelectric devices ${ }^{[7]}$ and multiple capacitors. By varying the concentration of dopants, the properties of $\mathrm{SrTiO}_{3}$ could be modified for functional purposes in normal capacitors and convoluted microwave devices and to control the electrical properties ${ }^{[8,9]}$. When $\mathrm{SrTiO}_{3}$ is used as a photoanode accompanying platinum counter electrode in the absence of external bias, can disintegrate water into $\mathrm{H}_{2}$ and $\mathrm{O}_{2}{ }^{[10]}$. The visible emission was ascribed to self-trapped excitons and is compared with particle size as well as intrinsic surface states and defect centers by a strong electron-phonon interaction ${ }^{[1]}$. $\mathrm{SrTiO}_{3}$, being a significant part of titanate family and due to its excellent chemical and physical properties can act as a promising and potential photocatalyst for providing green energy by $\mathrm{H}_{2}$ evolution ${ }^{[8,9]}$. Up to now, various chemical approaches for synthesizing $\mathrm{SrTiO}_{3}$ nanoparticles, such as sol-gel technique ${ }^{[12]}$, precipitation method ${ }^{[13]}$, hydrothermal ${ }^{[14]}$, solvothermal ${ }^{[15]}$, solidstate reaction method ${ }^{[16]}$, thermal decomposition method ${ }^{[17]}$, simple polymer solution route ${ }^{[18]}$ and so on, have been widely recorded.

Nevertheless, many of these methods require long reaction time, high external temperature or special instrumentation. We thus eliminated the complexities of methods mentioned above by establishing a simple solution combustion reaction. Solution combustion synthesis (SCS) has emerged as a significant technique for the synthesis and processing of advanced ceramics (structural and functional), catalysts, composites, alloys, intermetallics and nanomaterials. It was proved to be the simple, efficient and cost-effective which overcomes the above said synthetic difficulties making use of exothermicity of the self-maintaining chemical reaction to itself run the reaction. SCS method is useful for producing homogeneous, porous, fine crystalline powders and there is a possibility of using one-pot synthesis ${ }^{[19]}$.

Genki Saito et al. ${ }^{[20]}$ reported the synthesis of strontium titanate via solution combustion of titanium tetra-isopropoxide, strontium nitrate and glycine as the starting materials. Though $\mathrm{SrTiO}_{3}$ could be produced in good yield, the synthesis is a lengthy process comprising precipitation, rinsing in an ultrasonic bath and drying to form a sol-gel and finally submitting for the combustion process, to reach the final product. In large-scale production, this process is expensive, time-consuming and not much environmentally benign.

Recently, Kusuma et al., has used titanium metal powder for the synthesis of $\mathrm{CaTiO}_{3}$ nano-powder ${ }^{[21]}$ and here we have focused on the preparation of $\mathrm{SrTiO}_{3}$ nanoparticles via SCS route using strontium nitrate and titanium metal powder as an oxidizer and tartaric acid as fuel. The effect of oxidizer and fuel type on crystallite size, particle size, morphology and surface area are observed as well as photocatalytic degradation, photoluminescence and cyclic voltammetry properties of cubic perovskite $\mathrm{SrTiO}_{3}$ nanoparticles are investigated.

\section{Experimental}

\subsection{Chemicals}

Titanium metal powder ( $\sim 100$ mesh), strontium nitrate, hydrogen peroxide (30\%), aq. ammonia (30\%), tartaric acid (L $(+)$ ) were purchased from Merck Ltd., and mercuric chloride from Sd-fine Chemicals Pvt. Ltd. and used without further purification.

\subsection{Preparation of titanium-peroxo complex}

An aqueous solution of the titanium-peroxo complex as titanium source was prepared by dissolving $0.2 \mathrm{~g}$ titanium metal powder in $30 \%$ solution of $20 \mathrm{~mL} \mathrm{H}_{2} \mathrm{O}_{2}$ and $5 \mathrm{~mL}$ aqueous ammonia, on continuous stirring in an ice bath for 180 minutes. The plausible reaction mechanism for the formation of titanium-peroxo complex is as follows ${ }^{[22]}$ :

$$
\begin{array}{llll}
\mathrm{Ti}+3 \mathrm{H}_{2} \mathrm{O}_{2}+\mathrm{NH}_{3} & \longrightarrow & {\left[\mathrm{Ti}\left(\mathrm{O}_{2}\right)(\mathrm{OH})_{3}\right]^{-}+\mathrm{H}_{2} \mathrm{O}+\mathrm{NH}_{4}^{+}} & {[1]} \\
{\left[\mathrm{Ti}\left(\mathrm{O}_{2}\right)(\mathrm{OH})_{3}\right]^{+}+\mathrm{H}_{2} \mathrm{O}} & \longrightarrow & \mathrm{Ti}(\mathrm{OH})_{4}+(1 / 2) \mathrm{O}_{2}+\mathrm{OH}^{-} & {[2]} \\
\mathrm{Ti}(\mathrm{OH})_{4}+\mathrm{H}_{2} \mathrm{O}_{2} & \longrightarrow & {\left[\mathrm{Ti}\left(\mathrm{O}_{2}\right)(\mathrm{OH})_{3}\right]^{-}+\mathrm{H}_{3} \mathrm{O}^{+}} & {[3]}
\end{array}
$$




\subsection{Synthesis of $\mathrm{SrTiO}_{3}$ nanoparticles}

In a typical reaction, the titanium-peroxo complex $\left[\mathrm{Ti}\left(\mathrm{O}_{2}\right)(\mathrm{OH})_{3}\right]^{-}$was taken in a $100 \mathrm{~mL}$ beaker and to this $0.8843 \mathrm{~g}$ strontium nitrate ( $\mathrm{Ti}: \mathrm{Sr}=1: 1)$ as oxidizer and $3.03 \mathrm{~g}$ tartaric acid as a fuel (Oxidizer: Fuel = 1:5) were added. Then the homogeneous reaction mixture obtained after evaporation of excess liq. $\mathrm{NH}_{3}$ and $\mathrm{H}_{2} \mathrm{O}_{2}$ over the hot plate is subjected to combustion in a muffle furnace maintained at $550 \pm 10^{\circ} \mathrm{C}$. Initially, the reaction mixture goes through dehydration by forming a froth, which fills the beaker within a minute and then pursued by the smoldering combustion. Then voluminous and the porous black-colored product was formed which on calcination at the same temperature for 30 min resulted in non-carbonaceous and pure $\mathrm{SrTiO}_{3}$ nanoparticles.

\subsection{Photocatalytic experiment}

The photocatalytic activity of as-synthesized $\mathrm{SrTiO}_{3}$ nanoparticles was estimated by measuring the degradation of Amaranth R. I (ARI) dye in water under the illumination of UV-light using Hg-lamp.

An aqueous suspension was primed by the addition of $300 \mathrm{mg} \mathrm{SrTiO}$ nanoparticles to a $200 \mathrm{~mL}$ solution containing 5 ppm ARI dye in a pyrex dish. Then the prepared aqueous suspension was magnetically stirred in the dark compartment at room temperature for about $30 \mathrm{~min}$ to ascertain the adsorption/desorption equilibrium. During the photocatalytic experiment, the slurry composed of catalyst and dye solution was established in the reactor and magnetically stirred for agitation with simultaneous exposure to UV light. At a specific time of gap, samples were withdrawn to remove the catalyst particles by centrifugation to quantify the amount of decolorization. The concentration of ARI dye was monitored by measuring the absorbance of solution using a UV-Vis spectrophotometer at $520 \mathrm{~nm}$. The efficiency of decolorization was resolved by using the following expression:

Decolorization efficiency (\%) $=\frac{\mathrm{C}_{\mathrm{i}}-\mathrm{C}_{\mathrm{f}}}{\mathrm{C}_{\mathrm{i}}} \times 100$

where $C_{i}$ and $C_{f}$ are the initial and final dye concentrations respectively.

\subsection{Electrode modification}

The GCE surface was polished on a polishing pad with aqueous slurry of alumina powder $\left(\alpha-\mathrm{Al}_{2} \mathrm{O}_{3} 1.0\right.$ and $\left.0.3 \mu \mathrm{m}\right)$ till it gave a mirror like finished surface. Further, the electrode was washed with double distilled water and left to dry under infrared lamp. This procedure was followed before each electrochemical measurement. The as prepared $\mathrm{SrTiO}_{3}$ was dispersed in water $(2 \mathrm{mg} / \mathrm{mL})$ and was sonicated for 10 minutes. Further, $5 \mu \mathrm{L}$ of the dispersion was casted on the glassy carbon electrode surface and was dried under infrared lamp.

\subsection{Analytical procedure}

For electrochemical characterization, an aliquot of stock solution of $\mathrm{Hg}$ (II) was taken into standard volumetric flask and further diluted to appropriate volume and this solution was then transferred to an electrochemical cell to carry out electrochemical experiments. The voltammograms were recorded using differential pulse anodic stripping voltammetry (DPASV) technique under the optimized parameters (frequency, $15 \mathrm{~Hz}$; amplitude, $25 \mathrm{mV}$ and increment potential, 4 $\mathrm{mV}$ ). The solution was stirred using a magnetic stirrer at $300 \mathrm{rpm}$ which promoted the accumulation of $\mathrm{Hg}$ (II) ions on the electrode surface. Then commanded a reduction potential of $-0.4 \mathrm{~V}$ in order to reduce all the preconcentrated metal ions into its atomic state and subsequently stripped off from the electrode interface to the bulk of the electrolytic solution after the quiescent time of $30 \mathrm{~s}^{[23]}$.

\section{Powder characterization}

The phase formation and crystal structure of as-synthesized $\mathrm{SrTiO}_{3}$ nanoparticles are scanned by powder X-ray diffraction (PXRD) measurement using PANalytical X'pert PRO MPD instrument with graphite-filtered CuK $\alpha$ radiation source $(\alpha=1.541 \AA$ ). The diffuse reflectance spectrum (DRS) was measured using UV - Visible spectrometer (Shimadzu 3101) of the wavelength range from $200-800 \mathrm{~nm}$. Nitrogen adsorption-desorption isotherm (77 K) and pore size distribution measurements were carried out using a gas sorption analyzer (Quantachrome Corporation NOVA 1000). The photoluminescence study at room temperature was performed on a Perkin-Elmer LS-55 luminescence spectrometer using Xe lamp. Thermogravimetric analysis was performed from 50 to $800{ }^{\circ} \mathrm{C}$ with a heating rate of 10 
${ }^{\circ} \mathrm{C} \min ^{-1}$ using TGA 4000, Perkin Elmer instrument. The morphologies of the synthesized material were analyzed by scanning electron microscopy (SEM) JEOL-JSM-6490 LV. The sample has been coated with a thin layer of platinum prior to SEM analysis. The nano/microstructure and particle size were observed by high resolution transmission electron microscopy (TEM/HRTEM JEOL JEM 2100). Electrochemical measurements were carried out using CHI 6194 B (CH Instruments, Texas, USA) electrochemical workstation at room temperature in a glass cell comprising a platinum wire counter electrode, a $\mathrm{Ag} / \mathrm{AgCl}$ (saturated $\mathrm{KCl}$ ) reference electrode $(\mathrm{CH}$ Instruments, Texas, USA) and modified or unmodified glassy carbon $(\mathrm{GC})$ electrode $($ dia. $=3 \mathrm{~mm})$ as working electrodes $(\mathrm{CH}$ Instruments, Texas, USA). The solutions were degassed using nitrogen gas for $10 \mathrm{~min}$., prior to electrochemical measurements. All $\mathrm{pH}$ measurements were carried out using Control Dynamics pH meter (APX 175).

\section{Results and discussion}

Figure 1 shows a distinctive powder XRD pattern of $\mathrm{SrTiO}_{3}$ nanoparticles prepared by the solution combustion method. The result reveals that all diffraction peaks (100), (110), (111), (200) and (211) in the data can be indexed to the cubic perovskite structure of $\mathrm{SrTiO}_{3}$ nanoparticles with $\mathrm{Pm}-3 \mathrm{~m}$ space group. The measured lattice parameters of this cubic phase are $\mathrm{a}=3.9050$ and $\mathrm{Z}=1$ which is in good agreement with the reported data and JCPDS number: $35-$ 734 respectively. The broadness of the peaks signifies the good nanocrystalline nature of $\mathrm{SrTiO}_{3}$ nanoparticles and the crystallite size calculated from the Scherrer's formula is $\sim 18.28 \mathrm{~nm}$.

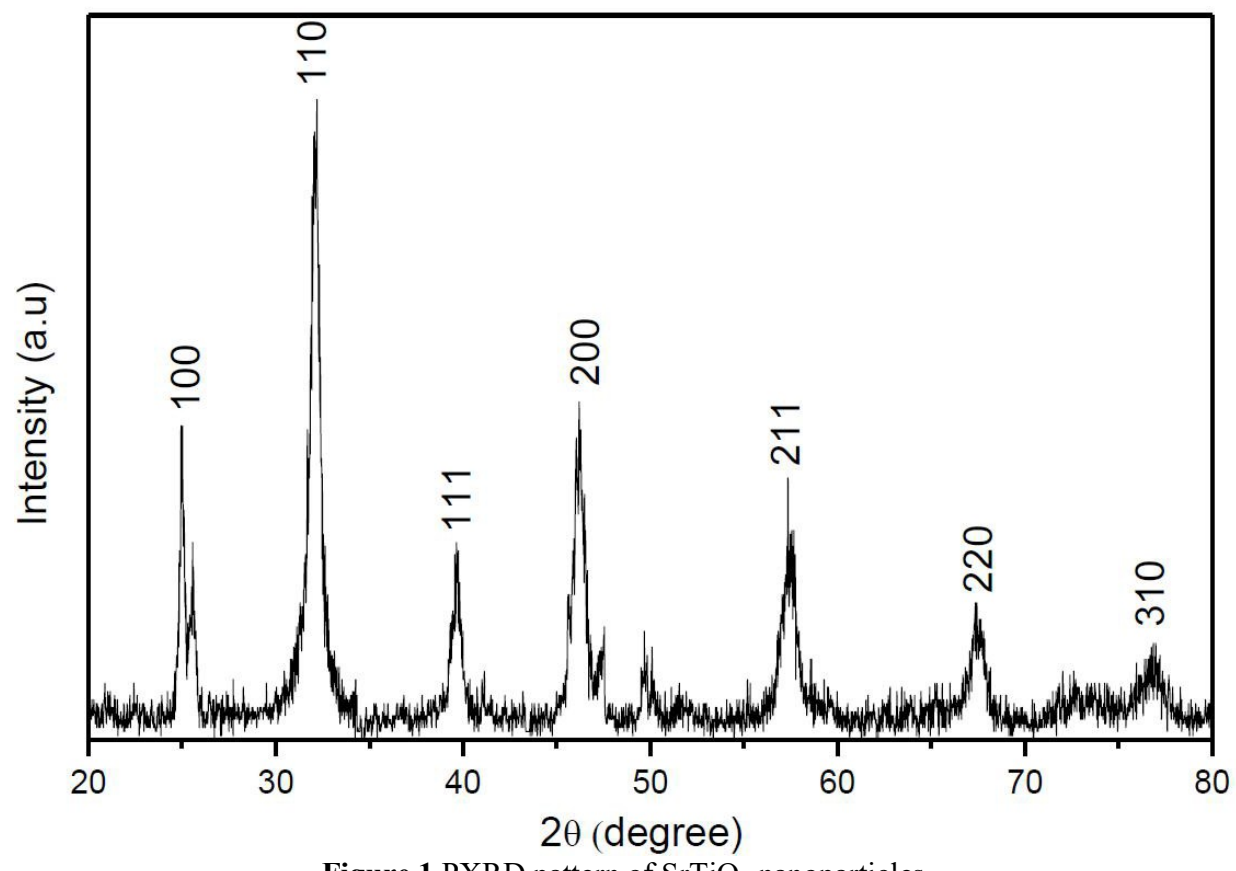

Figure 1 PXRD pattern of $\mathrm{SrTiO}_{3}$ nanoparticles.

Figure 2a and $\mathbf{2 b}$ exhibits a characteristic adsorption-desorption isotherm of nitrogen $(77 \mathrm{~K})$ and pore size distribution curve of $\mathrm{SrTiO}_{3}$ nanoparticles. As per Brunauer-Deming-Deming-Teller and IUPAC classification, $\mathrm{SrTiO}_{3}$ exhibits type IV isotherm with type $\mathrm{H} 3$ hysteresis. The type IV isotherm implies the presence of mesopores in the $\mathrm{SrTiO}_{3}$ nanoparticles and this was proved by the results of pore size distribution measurements ${ }^{[24]}$. The large number of mesopores is uniformly distributed in $\mathrm{SrTiO}_{3}$ nanoparticles at $\sim 48.47 \mathrm{~nm}$ as average pore diameter with pore volume $0.062 \mathrm{cc} / \mathrm{g}$. The measured Brunauer-Emmett-Teller (BET) surface area of $\mathrm{SrTiO}_{3}(26.51 \mathrm{~m} / \mathrm{g})$ is nearly 1.6 to 2.2 times more than that of the $\mathrm{SrTiO}_{3}$ synthesized using Glycine-nitrate-based solution-combustion $\left(12.24 \mathrm{~m}^{2} / \mathrm{g}-16.79\right.$ $\left.\mathrm{m}^{2} / \mathrm{g}\right)^{[20]}$.

The surface morphology of the combustion-derived $\mathrm{SrTiO}_{3}$ nanoparticles in Figure 3a and 3b shows layered membrane-like structure. The thermal treatment for the exclusion of carbon results in agglomeration and there is a perceptible increase in the thickness of these membranes. It is perceptible that numerous pores and voids can also be noticed in this SEM images. It is for the reason that in combustion synthesis the reaction turns up in short period of time with the evolution of lot of gases that normally yields nanosized materials with pores and voids. 

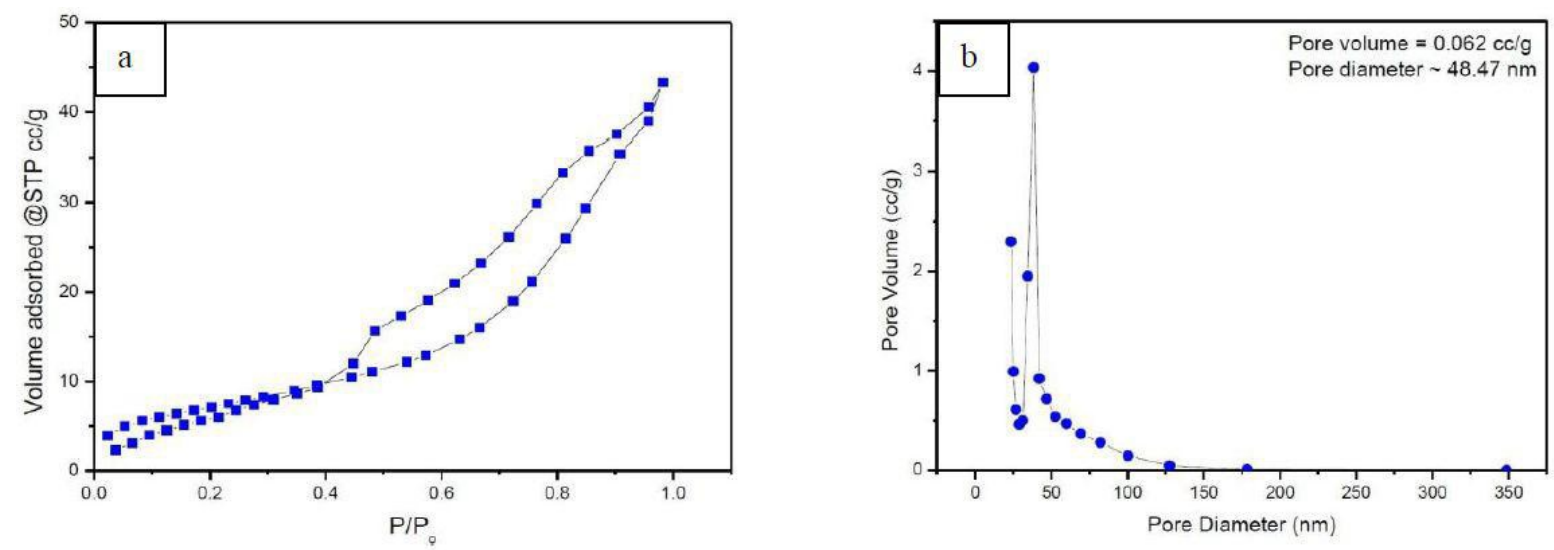

Figure 2 (a) Nitrogen adsorption-desorption isotherm of $\mathrm{SrTiO}_{3}$ nanoparticles and (b) Corresponding pore-size curve of $\mathrm{SrTiO}_{3}$ nanoparticles

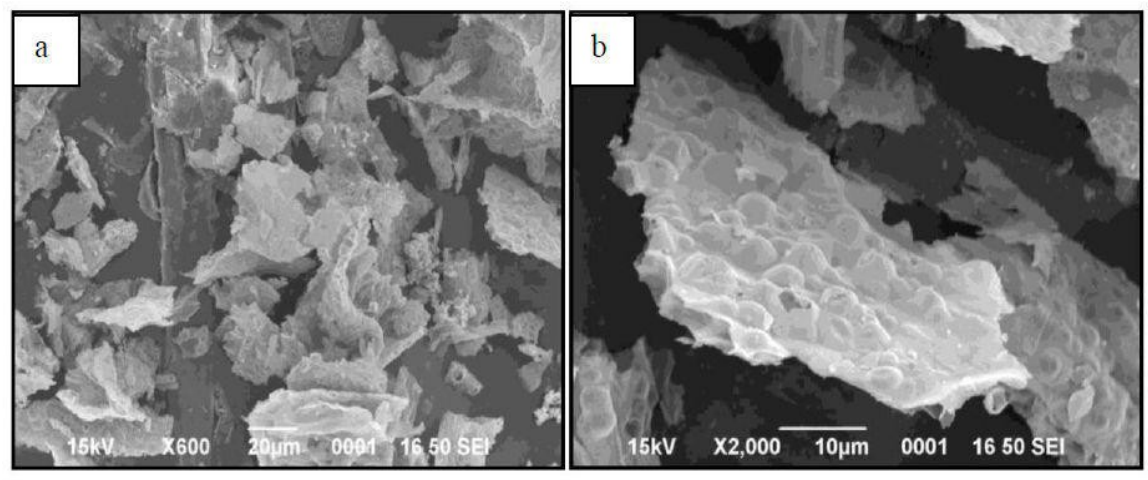

Figure 3 SEM images of $\mathrm{SrTiO}_{3}$ nanoparticles

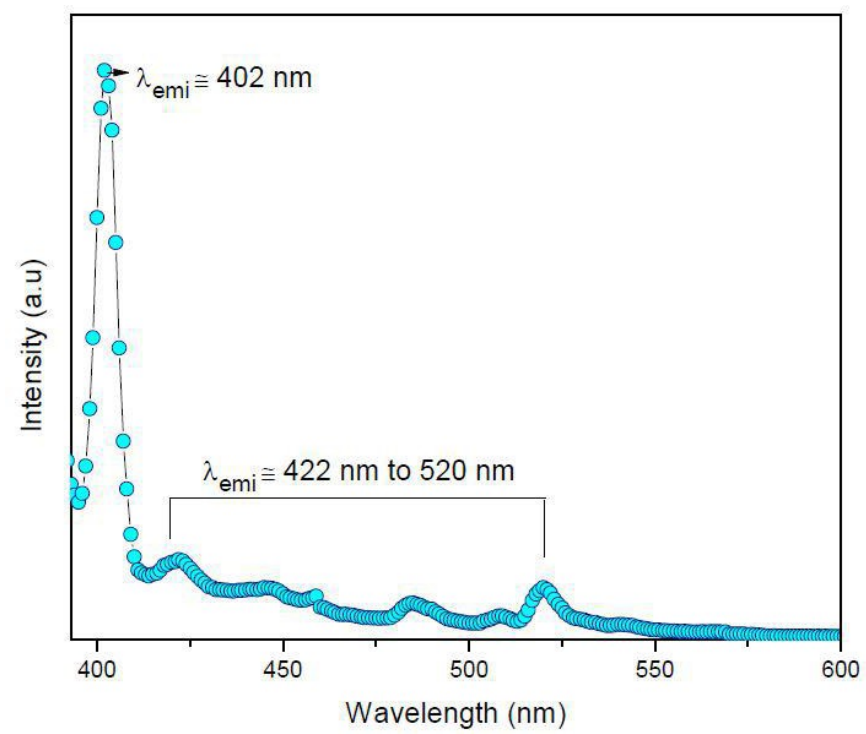

Figure 4 Photoluminescence spectrum of $\mathrm{SrTiO}_{3}$ nanoparticles.

In Figure 4, the PL spectrum is covering a large part of the visible spectrum, from 390 to $600 \mathrm{~nm}$. As can be seen, the $\mathrm{SrTiO}_{3}$ presents a high intense PL emission centered at $\sim 402 \mathrm{~nm}$ (violet-light emission) and shorter intense PL emission centered from $\sim 22$ to $520 \mathrm{~nm}$ (violet-blue-green-light emission). Hence, the interesting PL properties of structurally ordered-disordered $\mathrm{SrTiO}_{3}$ nanoparticles are governed by complex cluster vacancies.

Quantum mechanical calculations of disordered $\left[\mathrm{TiO}_{6}\right]$ and/or $\left[\mathrm{SrO}_{12}\right]$ clusters signify that localized states produced in the energy band gap will reduce the band energies. These interpretations establish the fact that PL is directly correlated with the localized states existing in the band gap, also the degree of order-disorder alter these localized states. Thus, the violet-blue-green emissions can be attributed to shallow and deep defects. 
As a result, each color represents a different type of electronic transition and is associated with a definite structural arrangement. The $\left[\mathrm{TiO}_{5} \cdot \mathrm{V}\right]$ and $\left[\mathrm{SrO}_{11} \cdot \mathrm{V}\right]$ complex clusters are associated with the band gap having shallow defects and lead to a more energetic PL emission [violet-blue-green light]. In PL emission, the intensity mainly depends on the interaction between these complex clusters and the excitation wavelength. These interactions could be investigated by the analysis of time-resolved spectroscopy which has been proved by Valeria et al ${ }^{[3,11]}$.

To examine the photodegradation viability of Amaranth R. I. (ARI) dye solution, experiments were carried under three different conditions: adsorption, photolysis and photocatalysis (Figure 5) where the $\mathrm{pH}$ of the solution mixture was $\sim 7$. In the case of photolysis (in the absence of catalyst) the negligible decolorization of the solution containing ARI was observed. Then the addition of a certain quantity of $\mathrm{SrTiO}_{3}$ nanoparticles in the irradiated medium clearly improved the rate of decolorization of the dye solution by the end of 180 minutes. Then the influence of adsorption of ARI on $\mathrm{SrTiO}_{3}$ was also examined (in the absence of light) which resulted in the insignificant decrease of residual dye concentration. This is due to the enhancement of $\mathrm{OH}^{\cdot}$ and $\mathrm{O}_{2}^{-\cdot}$ radicals in the solution. As the term photocatalysis is the combination of photochemistry with catalysis i.e., both light and catalyst are significant to stimulate a chemical reaction. Thus the photocatalytic process improves the rate of decolorization of the azo-dye, where both light and catalyst are necessary for the degradation of dye ${ }^{[25] \text {. }}$

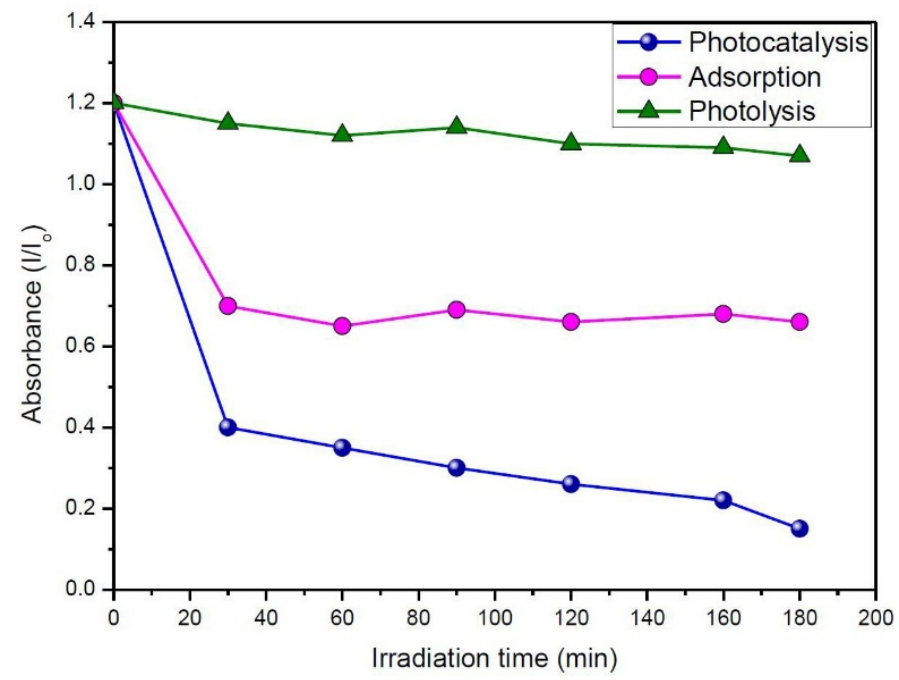

Figure 5 De-colorization of Amaranth R.I dye under different experimental conditions using $\mathrm{SrTiO}_{3}$ nanoparticles

It is distinct from the TEM image (Figure 6a) that the particles are well aggregated. It is due to the liberation of heat during the combustion process. In addition, TEM images show the well dispersed irregular shaped particles with an average size distribution ranging from 20-70 nm. The abundance of particles with different size is shown in Figure 6d with the size distribution histogram. The histogram was obtained by analyzing several frames of similar field images using the Digital Micrograph software.

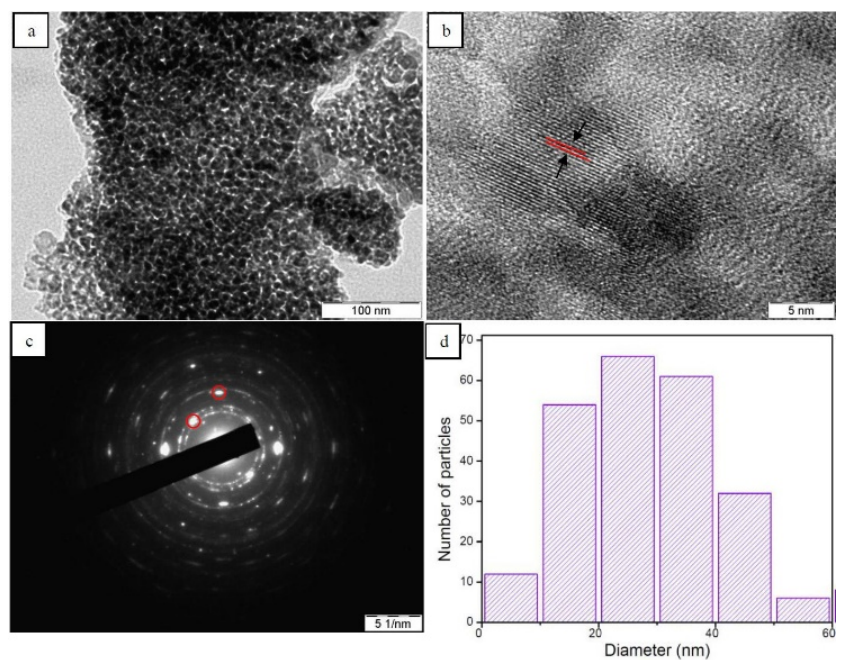

Figure 6 (a) TEM (b) HRTEM (c) SAED pattern and (d) Histogram graph of $\mathrm{SrTiO}_{3}$ nanoparticles 
Figure $6 \mathbf{b}$ shows typical HRTEM image of the sample where the size of the constituent particles is in the range of 5 $\mathrm{nm}$. The lattice spacing of $0.2 \mathrm{~nm}$ corresponds to (110) crystal planes, respectively of cubic perovskite phase of $\mathrm{SrTiO}_{3}$ nanoparticles. In the SAED pattern (Figure 6c) the spots are correlated to (110) and (111) crystal planes of $\mathrm{SrTiO}_{3}$ nanoparticles with polycrystalline nature.

\section{Electrochemical behavior of $\mathrm{SrTiO}_{3}$ modified electrode towards $\mathrm{Hg}$ (II) determination}

The electrocatalytic response of $\mathrm{SrTiO}_{3}$ modified electrode in the presence and absence of $\mathrm{Hg}(\mathrm{II})$ ions has been investigated in an aqueous medium utilizing electrochemical technique such as cyclic voltammetry (CV) and shown in

Figure 7. The CVs were recorded with bare glassy carbon electrode (bGCE) and $\mathrm{SrTiO}_{3}$ modified GCE in the potential range over -0.3 to $0.3 \mathrm{~V}$ in the presence of $0.1 \mathrm{M} \mathrm{HCl}$ as supporting electrolyte with a scan rate $50 \mathrm{mV} / \mathrm{s}$. Further, the modified glassy carbon electrode has not shown any current response for the oxidation of respective atomic metals into metal ions. Hence this could be used as an electrochemical sensing platform for the measurement of Hg(II) ions. The resulting voltammograms have shown well-defined oxidative peaks at the $\mathrm{SrTiO}_{3}$ modified electrode in the presence of $\mathrm{Hg}(\mathrm{II})$, which reveals that the $\mathrm{SrTiO}_{3}$ modified GCE could be used in the quantitative study. Further, in Figure 7 curve a represents $\mathrm{SrTiO}_{3}$ modified GCE which has not shown any analytical signal in the absence of Hg(II) ions whereas in the presence of $\mathrm{Hg}(\mathrm{II})$ presented in curve $\mathrm{c}$, it has exhibited an enhanced anodic peak current at a peak potential of 0.19 $\mathrm{V}$ and observed a weak split cathodic signals. The splitting of cathodic peaks is due to the uneven electrode surface formed during the drop coating method or it might be due to the extraneous redox processes occurring during electrochemical investigation ${ }^{[26]}$. Nevertheless, in curve $b$ the bGCE has shown an anodic peak current at the same peak potential in presence of $\mathrm{Hg}$ (II) in the same domain. From these results, it can be concluded that the use of $\mathrm{SrTiO}_{3}$ modified electrode can be used as promising electrochemical sensing interface for the quantification of $\mathrm{Hg}$ (II) ions from real sample matrices.

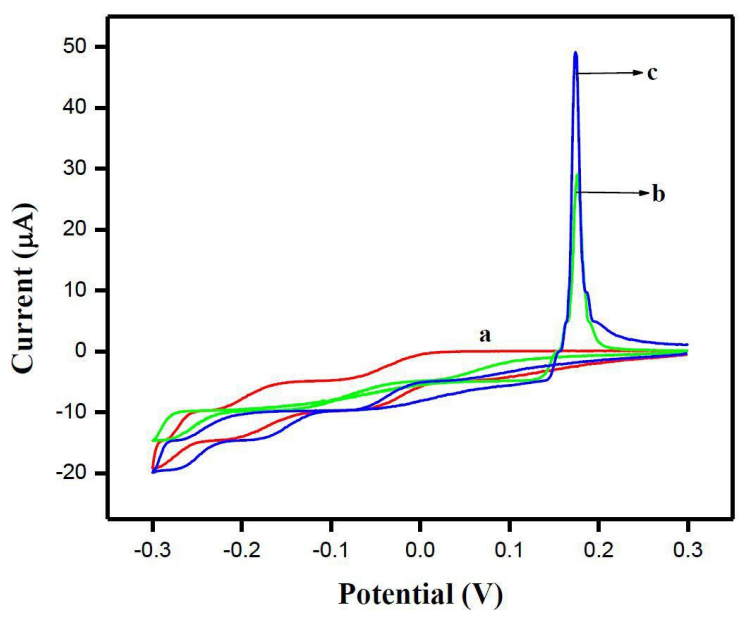

Figure 7 Overlaid cyclic voltammograms of (a) $\mathrm{SrTiO}_{3}$ modified electrode in the absence of $\mathrm{Hg}$ (II) (b) bare glassy carbon electrode and (c) $\mathrm{SrTiO}_{3}$ modified electrode in the presence of $10 \mathrm{ppm}$ of $\mathrm{Hg}(\mathrm{II})$ in $0.1 \mathrm{M} \mathrm{HCl}$ as supporting electrolyte with scan rate $50 \mathrm{mV} / \mathrm{s}$.

In order to achieve the maximum electrocatalytic efficiency of the $\mathrm{SrTiO}_{3}$ modified electrode in the electrochemical quantification $\mathrm{Hg}$ (II) ions, another sensitive electrochemical technique has been adapted in the present study such as differential pulse anodic stripping voltammetry (DPASV). Figure 8 represents the overlaid anodic stripping voltammograms of $\mathrm{Hg}(\mathrm{II})$ ions in presence of $10--400 \mathrm{ppb}$ in a $0.1 \mathrm{M} \mathrm{HCl}$ as supporting electrolyte at an applied potential of $-0.4 \mathrm{~V}$.

To examine the feasibility of the $\mathrm{SrTiO}_{3}$ modified electrode in practical applications, construction of the calibration graph under the optimized conditions in presence of a standard solution of $\mathrm{Hg}(\mathrm{II})$ ions plays an important role. Hence, the calibration plot (Figure 8 (inset)) has been constructed and showed linearity in the range 10-400 ppb with a correlation coefficient of 0.996 using DPASV and it has been performed by the successive addition of analytes into a stirred solution of the electrochemical cell at an applied potential of $-0.4 \mathrm{~V}$. The response of oxidation peak current of $\mathrm{Hg}(\mathrm{II})$ 
ions to the variation of concentration of metal ions increases linearly with the increase of its concentration up to 400 ppb with a limit of detection $(3 \sigma) 3.12 \mathrm{ppb}^{[26]}$.

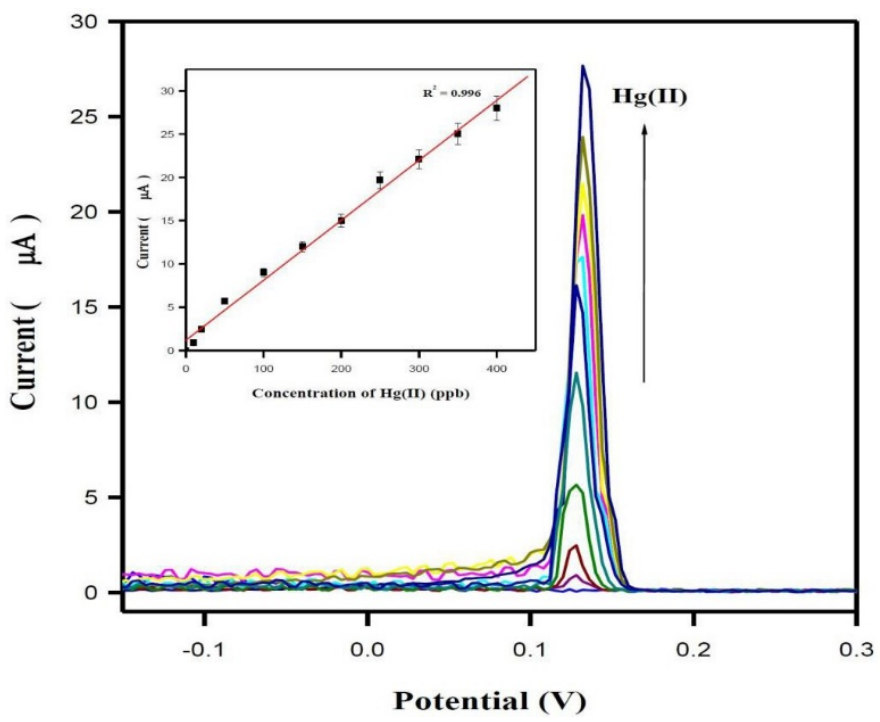

Figure 8 Overlaid differential pulse anodic stripping voltammograms of $\mathrm{Hg}(\mathrm{II})$ over the concentration range from $10-400 \mathrm{ppb}$ and calibration graph (inset)

\section{Conclusions}

In this report, we have prepared pure $\mathrm{SrTiO}_{3}$ nanoparticles of crystallite size $\sim 18.28 \mathrm{~nm}$ with high surface area and mesoporous nature which is a good characteristic of photocatalyst by solution combustion method. The peak for the emission spectra was observed at $\sim 402 \mathrm{~nm}$ (violet emission) then which shift to blue-green light emission ( 422-520 $\mathrm{nm}$ ). The optimization studies revealed good degradation of ARI dye only in the presence of UV-light and catalyst. Also $\mathrm{SrTiO}_{3}$ nanoparticles act as a promising electrochemical sensing for the quantification of $\mathrm{Hg}(\mathrm{II})$ ions.

\section{Acknowledgement}

One of the authors Kusuma $M$ is thankful to Bangalore University for extending financial support to carry out the present work.

\section{Conflict of interest}

The authors declare no conflict of interest.

\section{References}

1. Gertjan K, Boike L K, Guus J H M R, et al. Quasi-ideal strontium titanate crystal surfaces through formation of strontium hydroxide. Applied Physics Letters, 1998, 73(20): 2920-2922. doi: 10.1063/1.122630.

2. Jeffrey J U, Wan S Y, Qian G, et al. Synthesis of single-crystalline perovskite nanorods composed of barium titanate and strontium titanate. Journal of the American Chemical Society, 2002, 124(7): 1186-1187. doi: 10.1021/ja017694b.

3. Valeria M L, Maria D G, Sampaio C, et al. On the photoluminescence behavior of samarium-doped strontium titanate nanostructures under UV light. A structural and electronic understanding. Physical Chemistry Chemical Physics Pccp, 2010, 12(27): 7566-7579. doi: 10.1039/B923281H

4. Slonczewski J C, Thomas H. Interaction of elastic strain with the structural transition of strontium titanate. Physical Review B, 1970, 1(9): 3599-3608. doi: 10.1103/PhysRevB.1.3599.

5. Shelly B, Jacques E M, Keith B, et al. Nanocrystalline mesoporous strontium titanate as photoelectrode material for photosensitized solar devices: Increasing photovoltage through flatband potential engineering. The Journal of Physical Chemistry. B, 1999, 103(43): 9328-9332. doi: 10.1021/jp9913867.

6. Gerblinger J, Meixner H. Fast oxygen sensors based on sputtered strontium titanate. Sensors \& Actuators B Chemical, 1991, 4 (1-2): 99-102. doi: 10.1016/0925-4005(91)80183-K

7. Yue L, Colin N, Deepanshu S, et al. Thermoelectric power generation from lanthanum strontium titanium oxide at room temperature through the addition of graphene. ACS Applied Materials \& Interfaces, 2015, 7(29): 1589815908. doi: 10.1021/acsami.5b03522. 
8. Ning W, Deting K, Hongcai H. Solvothermal synthesis of strontium titanate nanocrystallines from metatitanic acid and photocatalytic activities. Powder Technology, 2011, 207(1-3): 470-473. doi: 10.1016/j.powtec.2010.11.034

9. Tzeng W, Shih S. Template-free synthesis of hollow porous strontium titanate particles. Journal of the American Ceramic Society, 2014, 97(2014): 1-6. doi: 10.1111/jace.13319

10. Kazunari D, Akihiko K, Takaharu O, et al. Photocatalytic decomposition of water into hydrogen and oxygen over nickel(II) oxide-strontium titanate $\left(\mathrm{SrTiO}_{3}\right)$ powder. 1. Structure of the catalysts. Cheminform, 1986, 90(2): 292295. doi: 10.1021/j100274a018.

11. Longo V M, de Figueiredo A T, de Lázaro S, et al. Structural conditions that leads to photoluminescence emission in SrTiO3: An experimental and theoretical approach. Journal of Applied Physics, 2008, 104(2): 1046. doi: $10.1063 / 1.2956741$

12. Florian V, Tanja D, Gunter B, et al. Synthesis and characterization of strontium titanate nanoparticles as potential high temperature oxygen sensor material. Journal of Nanomaterials, 2006, 2006(1): 1-6. doi: $10.1155 / \mathrm{JNM} / 2006 / 63154$

13. Tang W, Chen D. Synthesis of strontium titanate nanometer crystallites using a peroxide-based route. International Journal of Applied Ceramic Technology, 2007, 4(6): 549-553. doi: 10.1111/j.17447402.2007.02166.x

14. $\mathrm{Xu} \mathrm{H}$, Wei S, Wang $\mathrm{H}$, et al. Preparation of shape controlled $\mathrm{SrTiO}_{3}$ crystallites by sol-gel-hydrothermal method. Journal of Crystal Growth, 2006, 292(1): 159-164. doi: 10.1016/j.jcrysgro.2006.04.089

15. Uyi Sulaeman, Shu Yin, and Tsugio Sato, "Solvothermal Synthesis and Photocatalytic Properties of NitrogenDoped $\mathrm{SrTiO}_{3}$ Nanoparticless. Journal of Nanomaterials, 2010, 629727(2010): 1-6. doi: 10.1155/2010/629727.

16. Luo S, Zhang J, Wang N. Kinetics of strontium titanate formation from solid state reaction between strontium carbonate and anatase. High Temperature Materials \& Processes, 2011, 26(1): 33-41. doi: 10.1515/HTMP.2007.26.1.33

17. Amala S M, Dhanaraj G, Bhat H L, et al. Synthesis of fine-particle titanates by the pyrolysis of oxalate precursors. Journal of Materials Science Materials in Electronics, 1992, 3(4): 237-239. doi: 10.1007/BF00703033

18. Sang J L, Pradheep T, Man J L. Synthesis and characterization of strontium titanate powder via a simple polymer solution route. Journal of Ceramic Processing Research, 2008, 9(4): 385-388.

19. Fa-tang L, Jingrun R, Mietek J, et al. Solution combustion synthesis of metal oxide nanomaterials for energy storage and conversion. Nanoscale, 2015, 7(42): 17590-17610. doi: 10.1039/C5NR05299H

20. Genki S, Yuki N, Norihito S, et al. Glycine-nitrate-based solution-combustion synthesis of $\mathrm{SrTiO}_{3}$. Journal of Alloys \& Compounds, 2015, 652: 496-502. doi: 10.1016/j.jallcom.2015.08.227

21. Kusuma M, Chandrappa G T. Studies on synthesis, characterization and applications of nano $\mathrm{CaTiO}_{3}$ powder. Current Nanomaterials, 2016, 1: 145-155. doi: 10.2174/2405461501666160805125748

22. Gowdaiahnapalya P N, Siddaramanna A, Pallellappa C, et al. An efficient and a novel route for the synthesis of titania via solution combustion of peroxotitanic acid. Materials Letters, 2013, 91: 272-274. doi: 10.1016/j.matlet.2012.09.103

23. Prashanth S A, Craig E B, Pandurangappa M. Amino-thiacalix[4]arene modified screen-printed electrodes as a novel electrochemical interface for $\mathrm{Hg}$ (II) quantification at a pico-molar level. Analytical Methods, 2017, 9: 6747-6753. doi: 10.1039/C7AY02468A

24. Sing K S W, Everett D H, Haul R A W, et al. Reporting physisorption data for gas/solid systems with special reference to the determination of surface area and porosity. Pure \& Applied Chemistry, 1985, 57(4): 603-619. doi: 10.1515/iupac.57.0007

25. Boukhennoufa A, Bouhelassa M, Zoulalian A. Photocatalytic degradation of solophenyl red 3 BL in an aqueous suspension of titanium dioxide. Journal of Advanced Chemical Engineering, 2011, 1: A110301. doi:10.4303/jace/A110301

26. Prashanth S A, Pandurangappa M. Amino-calix[4]arene modified graphite as an electrochemical interface for mercury(II) quantification. Materials Letters, 2016, 185 (2016): 476-479. doi: 10.1016/j.matlet.2016.09.010 